\title{
Does social mix reduce stigma in public housing? A comparative analysis of two housing estates in Melbourne
}

Katrina Raynor ${ }^{a}$, Laura Panza ${ }^{b}$, Camilo Ordóñez ${ }^{c}$, Mladen Adamovic ${ }^{d}$, Melissa A. Wheeler

a Melbourne School of Design, The University of Melbourne, Masson Rd, Parkville, VIC 3010, Australia

b Department of Economics, Faculty of Business and Economics, The University of Melbourne, Australia c School of Forest \& Ecosystem Science, The University of Melbourne, Australia

$\mathrm{d}$ Centre for Workplace Leadership, Department of Management and Marketing, Faculty of Business and Economics, The University of Melbourne, Australia

e Department of Management and Marketing, Faculty of Business and Economics, The University of Melbourne, Australia

Keywords: Public housing; Social housing; Stigma; Social mix; Housing estates; Contact theory

Paper available at: Raynor, K., Panza, L., Ordóñez, C., Adamovic, M., \& Wheeler, M. A. (2020). Does social mix reduce stigma in public housing? A comparative analysis of two housing estates in Melbourne.

Cities, 96, 102458. https://doi.org/10.1016/j.cities.2019.102458

\begin{abstract}
A B STRACT
In Australia and many other countries of the Global North, public housing estates are being dismantled and redeveloped to create mixed-income communities. Proponents of redevelopment argue that the introduction of private housing will reduce public housing residents' experiences of stigma. In this paper, we interrogate these assumptions by identifying the degree of stigma directed at the social housing system, the characteristics of those most likely to stigmatise, the impact of proximity to public housing estates on stigmatisation and the words used to describe social housing. Our empirical strategy relies on a multi-dimensional social housing stigma scale, cross-sectional ordinary-least-square regression analysis and a qualitative analysis of respondents' association with the term public housing. We find that a higher level of stigma is correlated with private residents, older respondents, lower incomes and those that have lived in their current neighbourhoods for longer. Drawing on social contact theory, we investigate contact with public housing residents as a predictor of stigmatisation. We find that intra-group contact, positive interactions between social and private residents and proximity to Kensington Estate, a mixed-tenure development, contribute to lower stigmatisation.
\end{abstract}

\section{Introduction}

Social housing is undergoing a significant transformation in many countries as part of a global trend of addressing 'problem' housing estates (August, 2014). In Australia, social housing is an umbrella term for both public housing delivered by the state and community housing provided by the not-for-profit sector. In this paper, we use the term 'social housing' when referring to the broader social housing system and 'public housing' when referring to specific housing estates. Australian state governments have pursued a policy of renewing public housing estates in recent decades, arguing that such activities reduce concentrations of poverty, lead to more cohesive communities and create more opportunities for public housing tenants (Arthurson, 2008). The US, UK and much of western Europe have similarly engaged in what Goetz (2013) has referred to as a 'dismantling' of public housing, often driven by the demolition of public housing to create space for mixedincome communities (Joseph \& Chaskin, 2010). 
These redevelopment efforts are often justified through a series of contested claims about location-based disadvantage and the benefits of social mix. Advocates argue that residents of high-poverty locales stand to benefit from the introduction of investors and middle-class residents in their neighbourhood and the attendant opportunities this affords, either through changes in area reputation or the entrance of additional businesses and services (Patulny \& Morris, 2012). Embedded in redevelopment activities is the assumption that reducing the concentration of lower-income households through the addition of middleclass households will allow public housing tenants and their neighbourhoods to shed the stigma with which they were formerly burdened (McCormick, Joseph, \& Chaskin, 2012). Policy rhetoric has even suggested that proximity to middle-class neighbours may encourage public housing tenants to become more 'virtuous' citizens (Arthurson, 2008) while existing psychology literature drawing on social contact theory often finds reduced stigmatisation in individuals with more frequent contact with traditionally stigmatised groups (Pettigrew, 1998).

However, such rhetoric is contested. The causal logic of social mix has been substantially questioned in scholarship and public debate with critical voices suggesting that social mix arguments often serve as a palatable justification for underlying neoliberal logics more concerned with generating profit from redeveloping inner-city land parcels (Arthurson, 2012). Similarly, critics have argued that the notion of middle-class 'role models' is deeply patronising and rarely supported in empirical studies (Arthurson, 2012). More recently, the sale of public land for private profit inherent in public housing renewal has been framed as a consequence of governmental fiscal austerity and a highly problematic lack of willingness of governments to invest in public goods (Raynor, 2018). In the context of public housing renewal, the impact of structural barriers to opportunity and diminishing government investment has been largely overshadowed by the public's preoccupation with the supposed social deviance of social housing residents (see Joseph, Chaskin, \& Webber, 2007).

Social housing residents often experience stigmatization (McCormick et al., 2012). While the definition of stigma varies between disciplines and scholars, it can be broadly defined as "an attribute, or characteristic, that conveys a social identity that is devalued in a particular social context" (Crocker, Major, \& Steele, 1998, p. 505). Stigmatisation can be extremely detrimental to individuals and communities by creating social distance and generating differential treatment and unequal outcomes for the 'out-group' (Hatzenbuehler, Phelan, \& Link, 2013). Such stigmatisation is linked to disruptions for the stigmatized group to multiple life domains such as access to resources, social relationships, coping behaviours and health (Hatzenbuehler et al., 2013). In the context of social housing, stigmatisation may be related to ethnicity (Hunt, 2010), location, or perceived character traits and welfare dependency (Keene \& Padilla, 2010). In this paper, we focus on housing status (i.e. being a social housing resident) as the basis of stigmatisation.

While much literature has investigated the stigmatisation of social housing residents in Australia (Palmer, Ziersch, Arthurson, \& Baum, 2004), the UK (Carnegie, Norris, \& Byrne, 2018) and the US (Keene \& Padilla, 2010), these studies have predominantly used qualitative methodologies typified by small sample sizes. Few studies have quantitatively examined the insights from existing studies. To expand this research stream, we conduct a survey study to analyse who is most likely to stigmatise and quantify the degree of stigmatisation directed towards social housing tenants. For this purpose, we developed a multidimensional measure of stigma, derived from the psychological literature on mental health stigma (Taylor \& Dear, 1981), and applied it to attitudes towards social housing. To complement this work, we also examine the narratives embedded in the stigmatisation process by analysing the words used by 
respondents to describe social housing, unpacking the value-laden terms used to vilify, pity, celebrate or 'other' social housing.

Further, drawing on social contact theory (Pettigrew, 1998) that suggests that familiarity leads to acceptance, we hypothesise that people with frequent contact with social housing tenants or housing are likely to exhibit less stigma. Relatedly, reflecting the implicit logic behind social mix programs discussed above, we hypothesise that residents living in or near a mixed-tenure development are less likely to stigmatise than those living near a mono-tenure estate. To this end, this study collects quantitative data on social housing resident stigma to measure the degree to which the levels of stigma differ depending on proximity to and interaction with two estates in Australia's second largest city, Melbourne. The two estates are the mixed-tenure Kensington Estate and the mono-tenure Flemington Estate. We selected these estates because they represent different stages of the process of creating mixed-income communities in Australian public housing estates. Kensington Estate underwent renewal from the late 1990 s to 2010 and is now a mixed-income community. Flemington, in contrast, is currently a monotenure estate that is anticipated to be redeveloped over the next five years to incorporate significant levels of private housing. Below we provide an overview of recent developments by the literature on stigma and social housing, and later describe our case studies. We then explain the empirical strategies of data collection and analyses, before discussing findings.

\section{The stigmatisation of social housing}

Mixed tenure development is often promoted as a mechanism for reducing the "blemish of place" (Wacquant, 2007) often associated with housing estates. Similarly, a large body of research draws on contact theory to argue that stigma may be reduced through increased contact between 'in groups' and 'out groups' (Lee, Farrell, \& Link, 2004). However, these arguments are strongly critiqued in the literature. Research has pointed to the persistent nature of stigma (Hastings \& Dean, 2003). Locational stigma is generated over time and tends to remain even after built form interventions (Norris, Byrne, \& Carnegie, 2018; Varady \& Matos, 2017) or to transition into more fine-grain delineations of 'good' and 'bad' places within a stigmatised neighbourhood. Similarly, while redevelopment might increase overall location reputation, it can lead to new types of internal stigma and surveillance within neighbourhoods (McCormick et al., 2012). The persistence of stigma may also apply to individuals even after they leave estates, with Keene and Padilla (2010) noting the continuing discrimination experienced by former residents of Chicago public housing estates even after their move to Eastern lowa. Studies investigating resident behavior in mixed-income developments have found close proximity to public housing tenants may lead to higher income households adopting deliberate coping strategies such as avoiding sharing lifts or public spaces to distance themselves from public housing tenants (Tach, 2009). Such strategies align with Lee et al.'s (2004) observation that heavy exposure to an 'out-group' may result in a 'tipping point' for a proportion of the population where contact erodes empathy and instead leads to avoidance tactics. These findings are particularly relevant in the context of public housing renewal projects predicated on increasing contact between stigmatised and non-stigmatised groups without firm evidence that such approaches are effective.

There is a large body of research concerned with stigmatised or 'bad' places and the ways in which individuals respond to such characterisations. Research suggests that living in stigmatised neighbourhoods may reduce social opportunities (Musterd \& Andersson, 2005) or negatively impact job opportunities (Bauder, 2002). Non-residents may choose not to visit an area, based on the neighbourhood's negative image and perceptions about the 'type' of person that lives there. A growing body of literature has investigated differences in the way 'insiders' and non-residents experience and perceive a neighbourhood (Hastings \& Dean, 2003). For example, Blokland (2008) showed that residents 
in a housing project in Connecticut share non-resident's views that living in subsidised housing is 'for failures.' However, this is not always the case. Palmer et al. (2004) found that residents of stigmatized neighbourhoods in Adelaide, South Australia, challenged stereotypes and assumptions by delineating subregions within their neighbourhood, distancing themselves from other 'bad' residents and overtly opposing negative stereotypes imposed on their neighbourhood. In contrast, there has been relatively little research investigating the characteristics of people most likely to stigmatise public housing neighbourhoods or residents. While not directly testing for stigma, Ziersch, Arthurson, and Levin (2018) found that residents who were financially comfortable and only spoke English were more likely to be supportive of tenure mix than those that spoke more than one language or were less financially secure. Reasons for support included a desire to avoid ghettoisation, build community and contribute to social role modelling. The desire to integrate social housing 'ghettos' may align with neighbourhood reputation studies that often find that people prefer neighbourhoods with socio-economic and ethnic characteristics that are similar to their own. For example, low-income households are likely to rank low-income neighbourhoods more highly than middle and high-income households (van Ham \& Feijten, 2008).

In Australia, social housing is largely viewed by the general population and policy makers as a failed system that exacerbates social and economic disadvantage and concentrates crime, social disorder and welfare dependency (Arthurson, 2008; Atkinson \& Jacobs, 2008; Ruming, 2015). Jacobs and Flanagan (2013) identify three key themes that structure narratives of public housing; a pathological framing that associates public housing tenants with the 'moral underclass' who have made poor lifestyle decisions; a structural narrative that links social housing to income inequality; and a managerial narrative that focuses on the failure of the welfare state to create opportunities for residents to gain employment and enter mainstream society. Reflecting on these narratives, they call for a greater engagement with the structural narrative to help to counteract stigma, guide better policy outcomes and draw attention to the underfunded and residualised nature of the social housing system.

The concept of 'the ghetto' also appears frequently in Australian narratives, both in 'outsider' constructions circulated by the media, members of the population and policymakers and in 'insider' perceptions of those living on estates (Arthurson, Darcy, \& Rogers, 2014). Internationally, media stories disproportionately emphasise negative portrayals of public housing, circulating stories pertaining to asylum seekers and refugees, instances of racial tension, crime, violence, deprivation, overcrowding and poor design (Kearns, Kearns, \& Lawson, 2013). While efforts to counteract these negative portrayals are apparent in recent documentaries and social movements (Lucine, 2018), social housing and its residents remain a largely vilified population in Australia.

\section{Case study and social housing in Melbourne, Australia}

The stigmatisation of public housing estates in Australia is partially a reflection of historical cycles of (dis)investment in housing and social welfare. The height of social housing construction occurred in the 1950s and 1960s in Australia, in response to the need to house returning servicemen and working-class families (Hayward, 1996). Housing built at this time often took the form of hastily-constructed high-rise towers surrounded by much lower-density neighbourhoods. Since this time, consistent underfunding of social housing has resulted in an aging and poorly-maintained stock of housing and increasingly tightly rationed access to housing aimed at only the most vulnerable households (Raynor, 2018). Consequently, most tenants living in social housing have multiple vulnerabilities, with over $50 \%$ of tenants either receiving the majority of their income from a disability pension or aged pension and only $8 \%$ receiving the majority of their income from paid employment (Australian Institute of Health and Welfare, 2018). 
Public housing redevelopment to generate mixed-income communities is prevalent in Australia, where the integration of private housing in public housing estates is currently being replicated in inner-city sites across the country. This study was conducted in the rapidly gentrifying inner-west suburbs of Melbourne. Melbourne is the capital of Victoria and the second largest city in Australia (Fig. 1). This area was chosen as a case study due to the location of two public housing estates, chosen due to the timing of their redevelopment processes; Kensington and Flemington. Kensington Estate is notable as the first largescale public housing estate to undergo mixed-tenure renewal in Melbourne. Large proportions of Kensington Estate were demolished between 1999 and 2002 and a private developer completed redevelopment in 2012 resulting in a mixed-income community with a 47:53 split of public and private dwellings (Shaw, 2017). In 2017 the Victorian government announced a Public Housing Renewal Program (PHRP), committing to redeveloping a further nine sites across Melbourne by partnering with consortia of for-profit and not-for-profit actors to deliver private and social housing. The first site designated to undergo renewal is the Flemington Estate, located just $3 \mathrm{~km}$ from the Kensington Estate in Melbourne's inner-western suburbs (Fig. 1).

\section{Methods}

\subsection{Survey design \& data collection}

Data were collected from public housing and private residents in and around the two-case study public housing estates using a tailored and exploratory survey design based on convenient sampling recruitment strategies (Dillman, Smyth, \& Christian, 2014). Non-random, nonprobabilistic, and convenient sampling techniques were employed given the mixed qualitative/quantitative social research design of the study, which had the goal of gathering data from people that had the most relevant and immediate experience of the public housing estates. The survey was designed to a) measure levels of stigma displayed by the respondents, b) identify the characteristics of people who report a highlevel of stigma, c) assess whether proximity to public housing estates or interaction with social housing residents impacts stigma, and d) identify the concepts associated with social housing. The survey was co-created by an inter-disciplinary team of researchers and workshopped and reviewed by a group of ten local residents from both public housing estates.

Stigma was measured using a multidimensional scale derived from a mental health stigma scale (i.e., CAMI scale; Taylor \& Dear, 1981). While such multidimensional scales are usually only used with members of the 'in-group' (those not experiencing stigma) this study sought to also assess levels of internalised stigma by 'out-groups,' and so we delivered the scale to both public and private residents in the study area. A focus-group discussion with public housing residents revealed that our original more detailed and standardised stigma scales, based on a combination of both positive and negative statements about social housing tenants, were wholly inappropriate and offensive for potential respondents currently residing at public housing estates. Instead, this original scale was reworked to combine fewer negative statements with more positive statements (Table 1). We also generated a second alternative social housing resident stigma survey specifically focused on the respondent's neighbourhood to add replication and validity to the survey and based on perceptions of social housing often communicated in media portrayals (Item 10, Table A1). We also measured quality of interactions with public housing residents, by frequency of contact (Item 8, Table A1), as well as attitudes and preferences towards diversity (Item 11, Table A1) and a person's satisfaction of her own residential environment (Item 12 , Table A1), all based on independently developed multi-dimensional scales. Private housing residents were also asked how often they interacted with public housing residents and/ or visited each of the estates (Item 8, Table A1) and to describe the quality of their interactions (Item 9, Table A1). To identify the ideas associated with social housing the survey also included a question that asked respondents to list the first five words that came to mind when they thought of social housing (Item 6, Table A1). 
To test the impact of location and interaction with public housing residents, the survey also prompted respondents to indicate approximately where they lived by clicking on a map (online) or by placing a cross near their home (paper surveys; Item 5, Table A1). This approach was chosen in response to piloting processes that found a high level of discomfort with providing addresses in the respondent cohort. Locations indicated in the map were converted into coordinates to create a spatially referenced database of responses using ArcGIS (v. 10.4, Fig. 1).

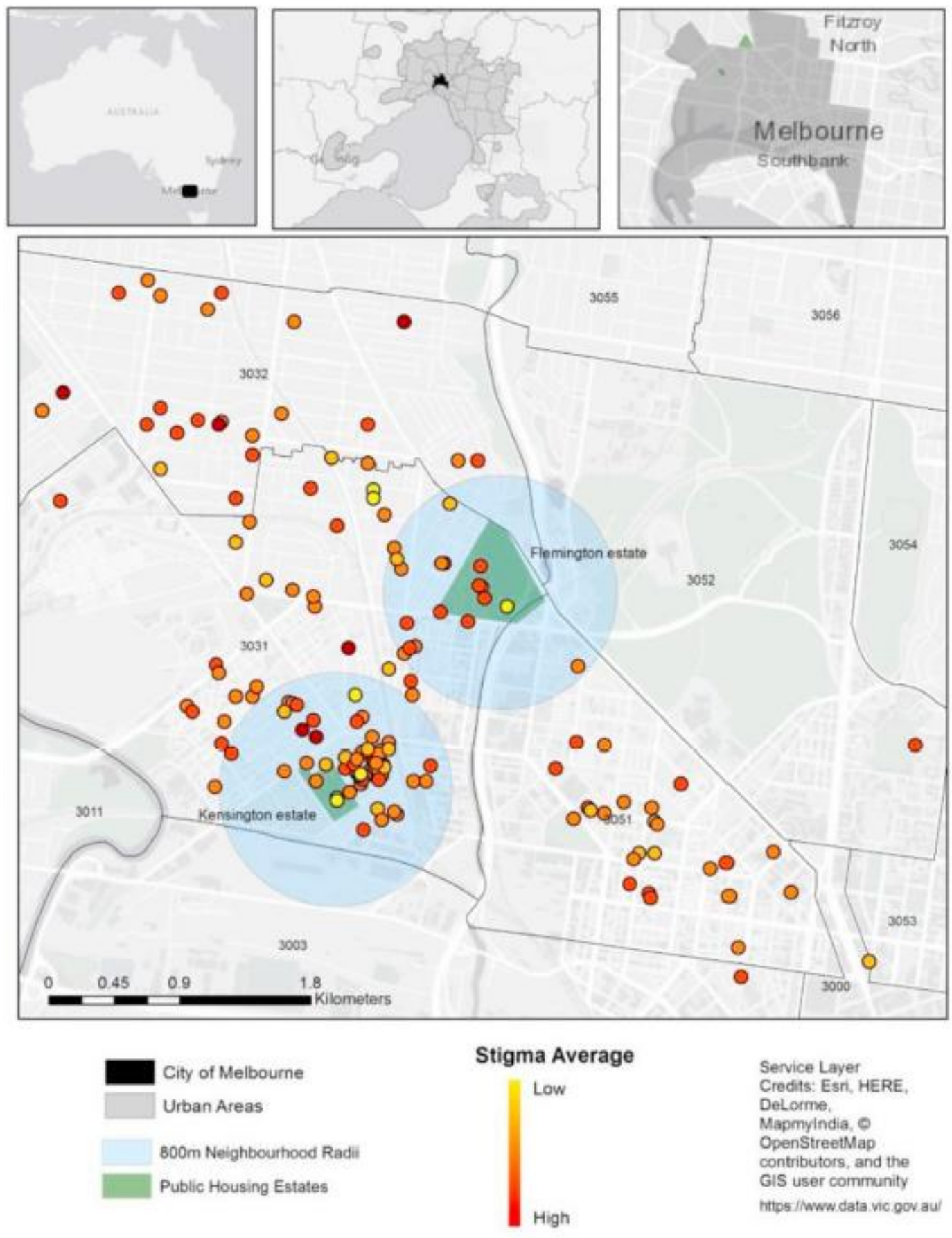


Fig. 1. Location of case study area, indicating public housing estates, neighbourhood area, postal codes of relevant studied areas, location of private housing respondents and their associated stigma directed at social housing residents.

Once the survey design was finalised, the surveys were made available online using Qualtrics. The surveys were delivered by recruiting participants via a variety of channels. Across channels, the survey was available in English and Chinese. Two local residents, one a public housing resident and one a private housing resident, were hired as research assistants to conduct in-person intercept surveys using an iPad or paper surveys. The research assistants conducted surveys while within and near the estates and attended local community activities like Chinese language classes or community lunches to collect responses. The survey was also made available online for anyone in the community willing to participate in the study and was advertised via local Facebook groups and posters in community centres. Printed surveys were also provided in a popular local café, pharmacy, and doctors surgery close to the estates along with submission boxes. These invitations were placed approximately in a $800 \mathrm{~m}$ radius from each of the estates, which defined the boundaries of the neighbourhoods (Fig. 1). The multiple collection methods reflect the realities of conducting research on a population characterised by low English proficiency, low access to computers and internet and historical distrust of opening the door for doorknocking researchers. Being exploratory in nature, this study did not collect data on how the participants filled the survey or how they came to know about it, but rather focused on collecting as much information as possible, while keeping track of a participant's background (see Table A1).

Table 1: Elements of the main multi-dimensional public housing resident stigma scale (item 7, Table A1).

\begin{tabular}{|c|c|c|}
\hline Maln questlon & Item (as a statement) & Measure \\
\hline \multirow{7}{*}{$\begin{array}{l}\text { Please rate how you agree with the } \\
\text { following statements }\end{array}$} & Social housing residents should live near the rest of the communtty & \multirow{7}{*}{$\begin{array}{l}\text { 1-5 Likert-based agreement scale, where } \\
1 \text { - strongly agree, } 5 \text { - strongly disagree. }\end{array}$} \\
\hline & Government should spend more maney an soclal housing & \\
\hline & It is easy to recognise a soclal housing resident from other people" & \\
\hline & Soclal housing residents make posittive contributions to the cormmunity & \\
\hline & I would prefer not to live next door to a soctal bousting restdent" & \\
\hline & $\begin{array}{l}\text { Nelghbourhoods with a mixture of public and private housing are better than } \\
\text { nelghbourhoods that only have private housing }\end{array}$ & \\
\hline & Soclal housing estates are places with great community spirtt & \\
\hline
\end{tabular}

* The rating in these statements is inverted (Le, more agreeance means more stigma).

\subsection{Data analysis}

The focus of the analysis was to empirically test the level of influence of a set of drivers on the level of stigma, as measured by our multidimensional stigma scale (Table 1). To facilitate the analysis, we generated a stigma index based on a simple average of all answers. Our baseline empirical specification aims at testing a set of stigma determinants, as described in the equation below:

Stigma $_{i}=B_{1}$ Private $_{i}+b_{2}$ Income $_{i}+b_{3}$ Residency length $_{i}+b_{4 x_{i}}+u_{i}(1)$

where the subscript $i$ indicates an individual, Stigmai stands for the stigma index, Privatei is a dummy variable taking the value of 1 if the respondent is a private housing tenant, Incomei denotes a person's income, and Residency lengthi stands for the number of years the respondent has lived in the neighbourhood, thus proxying for the intensity of connection to her place of residency, as well as neighbourhood exposure. Vector $X i$ includes standard demographic controls such as age and gender and ui is the error term.

We additionally controlled for country of birth and occupation fixed effects. These are aimed at capturing any time-invariant unobserved characteristics shared among people born in the same country (culture) 
and employed in the same occupation (ability, preferences) that may affect stigma. The standard errors are clustered at the country of birth level, as the residual ui is likely to be correlated for people born in the same country, given the persistence of cultural traits, which may influence attitudes towards stigma. Strong cultural persistence that lasts for generations has been documented among migrants and their descendants (see for example Algan \& Cahuc, 2010; Fernández, 2007).

In order to test the robustness of our findings, we use the alternative stigma index described in the previous section (Item 10, Table A1). Similar to the procedure we adopted with our main stigma index (Table 1), we generated an index based on an unweighted average of all answers in the alternative stigma scale. To allow for comparability, we constructed this index so that higher values are associated with stronger stigma (see items in Table 1). We also tested the validity of our results by combining the two indices, using the simple average of all ten stigma-related questions. The reliability of the stigma multidimensional scale and derived index (Table 1) was analysed by calculating Cronbach's alpha, which shows the internal validity of the scale items (see Table A2). In some specifications, we allowed for a richer set of control variables by adding the following dummy variables: for unemployed, for Australian-born respondents, for tenants and for welfare support recipients.

It can be argued that some contexts or conditions may intensify or weaken perceptions and sentiments towards the "other". To account for this, we also tested for the presence of heterogeneous effects and consider the following contexts: the quality of interactions between with public housing residents; general attitudes towards diversity and the level of satisfaction with one's own residential arrangements. To be clear, we are interested in testing whether having had good interactions with public housing tenants, valuing ethnic and linguistic diversity, and being satisfied with living space and conditions changes private residents' stigmatisation of public housing tenants. In order to test these hypotheses, our estimating equation is:

Stigma $_{i}=b_{i}$ Private $_{i}+b_{2}$ Private $_{i} *$ context $_{i}+b_{3}$ context $_{i}+b_{4}$ Income $_{i}+b_{5}$ Residency length $_{i}+b_{6} X_{i}+u_{i}$

where contexti denotes a particular context (an indicator variable or an index), and all other variables are as defined previously for Eq. (1).

We started by analysing whether the type of interactions with public housing residents affected stigmatisation. One of the survey questions, asks: "Overall, what are your experiences with public housing residents like?" (Item 9, Table A1). We coded a good interaction equal to 1 if the respondent answered "extremely good or somewhat good", and zero otherwise. Conversely, we coded a bad interaction equal to 1 if the respondent answered "extremely bad or somewhat bad", and zero otherwise.

To further explore these issues, we also tested whether contact with public housing per se matters for stigma. To this end, we make use of the survey question, directed only to private residents, asking "How often do you meet/talk to social housing residents?" where respondents could differentiate between the Kensington and Flemington estates. The possible answers included frequency of contact in categorical variables (Item 8, Table A1).

We also analysed the role played by attitudes towards diversity. Specifically, we have constructed an index proxying "preference" towards diversity (Item 11, Table A1). After assigning numeric values to each answer, we generated a diversity index based on a simple average of all answers, with higher values pointing to stronger preferences towards living in a diverse place. We also constructed an index to proxy 
a person's satisfaction of her own residential environment, by analyzing the response to the question: "Please rate how satisfied you are with the following aspects of your home" (Item 12, Table A1).

We also explored whether living in a mixed-income neighbourhood differentially influences private residents' stigma attitudes. This exercise allows us to indirectly test whether the redevelopment of public housing in Kensington contributed to reducing location-based disadvantage, possibly by encouraging social mix. To do so, we exploited data on the residential location of each private resident's response to generate a variable that captures distance from Kensington and Flemington estates. We then restricted the sample to private resident only, and ran the same regression specifications as in Eq. (1), adding distance from estate as an additional control variable.Finally, we counted and coded the words elicited through a question that asked respondents to list the first five words that came to mind when thinking of social housing. We used grounded theory (Corbin \& Strauss, 1990) to identify overarching themes, thus allowing common themes to arise through inductive interpretation.

Table 2: Descriptive statistics

\begin{tabular}{|c|c|c|c|c|c|c|c|c|c|c|}
\hline \multirow[t]{2}{*}{ Variable } & \multicolumn{5}{|c|}{ Private residents } & \multicolumn{5}{|c|}{ Public housing residents } \\
\hline & Observations & Mean & Standard error & Min & $\operatorname{Max}$ & Observations & Mean & Standard error & Min & Max \\
\hline Stigma index & 144 & 3.74 & 0.75 & 1.57 & 5 & 131 & 3.43 & 0.64 & 2 & 5 \\
\hline Stigma index (alternative) & 144 & 3.47 & 0.53 & 2.20 & 5 & 130 & 3.22 & 0.67 & 1.6 & 4.8 \\
\hline Stigma index (combined) & 144 & 3.61 & 0.56 & 2.03 & 5 & 131 & 3.32 & 0.57 & 1.8 & 4.8 \\
\hline Residency length (years) & 144 & 6.74 & 3.74 & 1 & 15 & 131 & 6.75 & 3.28 & 1 & 15 \\
\hline Age & 144 & 42.9 & 15.15 & 19 & 99 & 131 & 46.1 & 20.6 & 18 & 99 \\
\hline Male & 144 & 0.31 & 0.46 & 0 & 1 & 131 & 0.59 & 0.49 & 0 & 1 \\
\hline Income $(000 \$)$ & 121 & 104.8 & 65.7 & 0 & 200 & 112 & 69.5 & 53.7 & 0 & 175 \\
\hline Unemployed & 144 & 0.22 & 0.41 & 0 & 1 & 131 & 0.53 & 0.50 & 0 & 1 \\
\hline Australian born & 144 & 0.69 & 0.46 & 0 & 1 & 131 & 0.66 & 0.47 & 0 & 1 \\
\hline Tenant & 144 & 0.35 & 0.48 & 0 & 1 & 131 & 0 & 0 & 0 & 0 \\
\hline Welfare recipient & 144 & 0.02 & 0.14 & 0 & 1 & 131 & 0.08 & 0.28 & 0 & 1 \\
\hline Diversity index & 130 & 2.85 & 1.29 & 0.25 & 5 & 126 & 2.95 & 1.31 & 0.05 & 5 \\
\hline House satisfaction & 144 & 4.06 & 0.70 & 2.33 & 5 & 131 & 3.87 & 0.81 & 2.17 & 5 \\
\hline
\end{tabular}

\section{Results}

We collected data from 275 respondents representing a wide range of demographic characteristics and present the summary statistics Table 2, broken down by private/public status. Of the 275 respondents, 144 respondents were public housing residents, while 131 respondents were private housing residents. The results of our baseline analysis of the determinants of stigma are presented in Table 2. Columns 1-3 control only Privatei, Residency lengthi and the demographic variables, while we add income from column 4 on. For private residents, our stigma index varied from 1.57 to 5, with a mean of 3.74 (SD=0.75): higher values are associated with stronger stigmatisation. This means that an average stigma index of 3.0 would be expected and represent a proxy for a 'neutral' attitude towards public housing. The average scores were similar across answers within the index, thus indicating there was not a specific component of the stigma index driving the results. The averages for each answer (A) were: $A 1=4.06 ; A 2=4.10 ; A 3=3.20$; $A 4=3.64 ; A 5=3.14 ; A 6=3.57$ (see Table 1 for the questions). The multi-dimensional scale was reliable and internally consistent (i.e., Cronbach alpha>0.8; see Table A2). The descriptive statistics indicate that stigmatisation is on average only slightly higher among private housing residents $(M=3.74 ; S D=0.75)$ than public housing residents $(M=3.43 ; S D=0.64)$, pointing to the existence of internalised stigmatisation among social housing tenants.

Our findings indicate that being a private resident is associated with higher stigma levels towards social housing tenants (Table 3). Specifically, the estimated coefficient suggests that being a private resident is associated with a $7 \%$ increase in stigmatisation (column 1). Residency length and age are also more conducive of stigma, while higher income is correlated with lower stigma. Specifically, a one standard 
deviation increase in income is associated with around $16 \%$ less stigma (column 4). These results are robust to the inclusion of country of birth fixed effects (columns 2,5 ) and occupation fixed effects (columns 3, 6).

In the remaining columns we add a richer set of dummy variables as covariates: the variable "being born in Australia" aims at teasing out the effect (if any) of being born in country rather than not. This variable may impact attitudes towards the 'other', given that in Australia many refugees are first placed public housing. In order to test the influence of potential unmeasured positional factors of private rental housing tenant, we include a dummy variable for tenancy status. As highlighted by Burke, Neske, and Ralston (2004), tenants may have different perceptions of social housing (according to this study, $46 \%$ of surveyed households living in private rental accommodation and in receipt of Commonwealth Rental Assistance, claim they would not consider applying for public housing because of its stigmatised status). Next, we control for being unemployed and receiving any type of welfare support (study support, disability pension, youth allowance, etc.). The direction of the impact of these two variables is not straight forward a priori: for instance, being unemployed or a welfare recipient may reduce stigma through empathy, given the higher need for assistance. At the same time, it may also increase stigma, consistently with the negative effect of financial hardship. It is also important to note that these two covariates are likely to have some effects that are intertwined with income: the goal of this empirical exercise is to test for their effect given income effects.

The coefficients of these additional variables are not precisely estimated, with the exception of being a welfare receiver (Table 3, col. 7-8), and the key results of our baseline regressions continue to hold. Finding that being a pension recipient correlates with higher stigma suggests that being in a situation of disadvantage does not necessary translate into empathy, but rather that it can reinforce a sense of social division. As a robustness check, we also report the regressions outcomes of adding each of these additional covariates one by one, rather than jointly, and without controlling for income for employment status and welfare recipients, in order to capture their impact net of income (see Table A3). The findings are similar to those of Table 3.

Table 3: Determinants of stigma, baseline results based on regression analyses

\begin{tabular}{|c|c|c|c|c|c|c|c|c|}
\hline \multirow[b]{2}{*}{ Explanatory vartable } & \multicolumn{8}{|c|}{ Dependent varlable stlgma index } \\
\hline & I & II & III & IV & $\mathrm{v}$ & VI & VII & VIII \\
\hline Private restdent & $\begin{array}{l}0.285 \cdots \\
(0.086)\end{array}$ & $\begin{array}{l}0.236 \cdots \\
(0.075)\end{array}$ & $\begin{array}{l}0.194 \\
(0.109)\end{array}$ & $\begin{array}{l}0.356 \cdots \\
(0.067)\end{array}$ & $\begin{array}{l}0.254 m \\
(0.084)\end{array}$ & $\begin{array}{l}0.245 \cdots \\
(0.083)\end{array}$ & $\begin{array}{l}0.348 \cdot \\
(0.141)\end{array}$ & $\begin{array}{l}0.396 * \\
(0.156)\end{array}$ \\
\hline Residency length & $\begin{array}{l}0.052^{+-} \\
(0.015)\end{array}$ & $\begin{array}{l}0.049 \cdots \\
(0.011)\end{array}$ & $\begin{array}{l}0.049^{-\prime} \\
(0.023)\end{array}$ & $\begin{array}{l}0.050^{\circ} \\
(0.015)\end{array}$ & $\begin{array}{l}0.037= \\
(0.007)\end{array}$ & $\begin{array}{l}0.048^{\circ} \\
(0.021)\end{array}$ & $\begin{array}{l}0.039^{\circ} \\
(0.008)\end{array}$ & $\begin{array}{l}0.038^{\cdots} \\
(0.007)\end{array}$ \\
\hline Age & $\begin{array}{l}0.006 \% \\
(0.003)\end{array}$ & $\begin{array}{l}0.012 \mathrm{~m} \\
(0.001)\end{array}$ & $\begin{array}{l}0.005 \\
(0.004)\end{array}$ & $\begin{array}{l}0.004 \\
(0.003)\end{array}$ & $\begin{array}{l}0.012-- \\
(0.003)\end{array}$ & $\begin{array}{l}0.003 \\
(0.004)\end{array}$ & $\begin{array}{l}0.010^{-} \\
(0.004)\end{array}$ & $\begin{array}{l}0.008 \\
(0.004)\end{array}$ \\
\hline Male & $\begin{array}{l}-0.159^{\circ} \\
(0.063)\end{array}$ & $\begin{array}{l}-0.175^{-1} \\
(0.050)\end{array}$ & $\begin{array}{c}-0.147 \\
(0.095)\end{array}$ & $\begin{array}{l}-0.148^{\circ} \\
(0.058)\end{array}$ & $\begin{array}{l}-0.158^{*} \\
(0.043)\end{array}$ & $\begin{array}{l}-0.087 \\
(0.076)\end{array}$ & $\begin{array}{l}-0.171 \cdots \\
(0.044)\end{array}$ & $\begin{array}{l}-0.158^{* \cdots} \\
(0.039)\end{array}$ \\
\hline Income & & & & $\begin{array}{l}-0.002 \cdots \\
0.00\end{array}$ & $\begin{array}{l}-0.002 \cdots \\
(0.001)\end{array}$ & $\begin{array}{l}-0.004 \cdot- \\
(0.001)\end{array}$ & $\begin{array}{l}-0.003 \cdots \\
(0.001)\end{array}$ & $\begin{array}{l}-0.003 \cdot r \\
(0.001)\end{array}$ \\
\hline Unemployed & & & & & & & $\begin{array}{l}-0.163 \\
(0.097)\end{array}$ & \\
\hline Welfare rectplent & & & & & & & & $\begin{array}{l}0.389 \cdots \\
(0.080)\end{array}$ \\
\hline AUS bom & & & & & & & $\begin{array}{l}-0.073 \\
(0.106)\end{array}$ & $\begin{array}{l}-0.107 \\
(0.106)\end{array}$ \\
\hline Tenant & & & & & & & $\begin{array}{l}-0.320 \\
(0.194)\end{array}$ & $\begin{array}{l}-0.313 \\
(0.196)\end{array}$ \\
\hline $\mathrm{COS}$ flxed effects & $\mathrm{N}$ & $\mathbf{Y}$ & $\mathrm{N}$ & $\mathrm{N}$ & $\mathbf{Y}$ & $\mathrm{N}$ & $Y$ & $Y$ \\
\hline Occupation flxed effects & $\mathrm{N}$ & $\mathrm{N}$ & $\mathrm{Y}$ & $\mathrm{N}$ & $\mathrm{N}$ & $\mathbf{Y}$ & $\mathrm{N}$ & $\mathrm{N}$ \\
\hline $\mathrm{N}$ & 275 & 275 & 272 & 234 & 234 & 231 & 234 & 234 \\
\hline R2 & 0.107 & 0.272 & 0.289 & 0.157 & 0.286 & 0.410 & 0.310 & 0.313 \\
\hline
\end{tabular}

Notes Robust standard errors, clustered at the country of birth level are reported in parenthesis. Statistical significance at the * $10 \%$ level, ** $5 \%$ level, and *** $1 \%$ level. $\mathrm{COB}=$ country of birth. 
We also report on the same regressions specification using our alternative stigma index (Table A4), the results of which confirm the robustness of our previous observations. Our findings are also robust to using the combined stigma index described above (see Table A5).

\subsection{Heterogeneity in stigma}

While our results consistently show that being a private housing resident is associated with higher levels of stigma, the presence of heterogeneous effects can affect this relationship and potentially augment or diminish this relationship. Using the empirical specification described in Eq. (2), we consider the following contexts: the quality of interactions between with public housing residents, the general attitudes towards diversity, and the level of satisfaction with one's own residential arrangements.

Of the 103 private resident respondents who had contact with public housing tenants, about half of them (52) reported positive interactions. The results of this additional analysis, illustrated in Table 4, columns $1-3$, indicate that positive interaction between private and public housing residents is conducive of less stigma, and that the opposite is true in the case of bad interactions between the two groups (columns 46). In order to further explore this set of results, we test whether contact with public housing per se mattered for stigma We obtained 127 answers from private residents and used them to generate a variable indicating frequency of contact: we find that contact between the two groups is rather uncommon: the mean values are 0.83 and 1.49 for Flemington and Kensington, respectively. We then add the frequency of contact variables as additional controls to our baseline regression specifications. The findings, reported in Table A6, reveal that accounting for interactions overturns our earlier results, implying that, while positive interactions correlate with lower stigma, interaction per se is not a significant factor.

Table 4: The effect of interaction quality on stigma, based on regression analyses

\begin{tabular}{|c|c|c|c|c|c|c|}
\hline & \multicolumn{6}{|c|}{ Dependent varlable: stlgma index } \\
\hline & I & II & III & IV & $\mathrm{v}$ & VI \\
\hline Bad interactions $x$ private restdent & $\begin{array}{l}0.702^{* * *} \\
(0.078)\end{array}$ & $\begin{array}{l}0.618^{* * *} \\
(0.042)\end{array}$ & $\begin{array}{l}0.538^{* * * *} \\
(0.120)\end{array}$ & & & \\
\hline Good interactions $x$ private restdent & & & & $\begin{array}{l}-0.547^{* * *} \\
(0.100)\end{array}$ & $\begin{array}{l}-0.462^{* * *} \\
(0.047)\end{array}$ & $\begin{array}{l}-0.358^{* *} \\
(0.134)\end{array}$ \\
\hline Private restdent & $\begin{array}{l}0.039 \\
(0.075)\end{array}$ & $\begin{array}{l}-0.01 \\
(0.076)\end{array}$ & $\begin{array}{l}0.022 \\
(0.067)\end{array}$ & $\begin{array}{l}0.575^{* 6 *} \\
(0.079)\end{array}$ & $\begin{array}{l}0.470 * * . * \\
(0.090)\end{array}$ & $\begin{array}{l}0.393^{* 0 *} \\
(0.099)\end{array}$ \\
\hline Residency length & $\begin{array}{l}0.044^{* * *} \\
(0.013)\end{array}$ & $\begin{array}{l}0.035^{* * * *} \\
(0.008)\end{array}$ & $\begin{array}{l}0.051^{* * * *} \\
(0.018)\end{array}$ & $\begin{array}{l}0.053^{* * *} \\
(0.013)\end{array}$ & $\begin{array}{l}0.041^{* 6.8} \\
(0.008)\end{array}$ & $\begin{array}{l}0.053^{* \cdots} \\
(0.018)\end{array}$ \\
\hline Age & $\begin{array}{l}0.002 \\
(0.003)\end{array}$ & $\begin{array}{l}0.009 * * * \\
(0.002)\end{array}$ & $\begin{array}{l}0.001 \\
(0.004)\end{array}$ & $\begin{array}{l}0.004^{*} \\
(0.003)\end{array}$ & $\begin{array}{l}0.011^{*+*} \\
(0.003)\end{array}$ & $\begin{array}{l}0.003 \\
(0.003)\end{array}$ \\
\hline Male & $\begin{array}{l}-0.181^{*+*} \\
(0.059)\end{array}$ & $\begin{array}{l}-0.172^{*+*} \\
(0.048)\end{array}$ & $\begin{array}{l}-0.134 \\
(0.081)\end{array}$ & $\begin{array}{l}-0.131 * \\
(0.050)\end{array}$ & $\begin{array}{l}-0.144^{* * *} \\
(0.045)\end{array}$ & $\begin{array}{l}-0.085 \\
(0.074)\end{array}$ \\
\hline Income & $\begin{array}{l}-0.002^{* 0 .} \\
(0.001)\end{array}$ & $\begin{array}{l}-0.002^{*+*} \\
(0.001)\end{array}$ & $\begin{array}{l}-0.004+\cdots \\
(0.001)\end{array}$ & $\begin{array}{l}-0.002^{* * *} \\
(0.001)\end{array}$ & $\begin{array}{l}-0.002 * \cdots \\
(0.001)\end{array}$ & $\begin{array}{l}-0.004^{* * *} \\
(0.001)\end{array}$ \\
\hline Country of birth fixed effects & $\mathrm{N}$ & $Y$ & $\mathrm{~N}$ & $\mathrm{~N}$ & $\mathbf{Y}$ & $\mathrm{N}$ \\
\hline Occupation flxed effects & N & $\mathbf{N}$ & $\mathrm{Y}$ & $\mathrm{N}$ & $\mathrm{N}$ & $\mathrm{Y}$ \\
\hline $\mathrm{N}$ & 234 & 234 & 231 & 234 & 234 & 231 \\
\hline R2 & 0.272 & 0.364 & 0.455 & 0.227 & 0.329 & 0.432 \\
\hline
\end{tabular}

Notes Robust standard errors, clustered at the country of birth level are reported in parenthesis. Statistical significance at the * $10 \%$ level, ** 59 level, and *** $1 \%$ level.

Next, we explore the role of attitudes towards diversity and of satisfaction with one's home. The results illustrate that having a positive attitude towards diversity (Table 5, columns 1-3) as well as higher levels of satisfaction with the place where one lives (Table 5, columns 4-6) are associated with lower stigma towards public housing tenants.

\subsection{Stigma in mixed-tenure versus segregated neighbourhoods}


In our last set of regressions, we investigate whether distance from social housing has an impact on private residents' stigma. The results, reported in Table 6, show that living further away from the Kensington estate increases stigma (columns 4-6), while there is no significant distance effect for Flemington (columns 1-3). This finding suggests that being closer to potential interactions with public housing residents reduces negative attitudes only in mixed income communities, where such interactions are more likely to happen. Indeed, our data show that Kensington residents living in close proximity or within the estate (within $200 \mathrm{~m}$ ), had more interactions with public housing residents: $79 \%$ of publicprivate residents contacts within a $200 \mathrm{~m}$ radius of the estates occurred in Kensington. Similarly $73 \%$ of the interactions between private and public residents within a $500 \mathrm{~m}$ radius of an estate occurred in Kensington. The share for $800 \mathrm{~m}$ radius is $91.3 \%$ (see Fig. 1).

\subsection{Narratives of social housing}

The narratives emerging from the survey help to unpack the statistical findings. The survey asked all respondents to list the first five words that came to mind when they thought about social housing. These are presented in Fig. 2 and Table 7.

The responses from private residents are indicative of the ways in which social housing tenants and public housing buildings are perceived.

A narrative of deficiency or disadvantage was central, with words like 'disadvantaged', 'poor,' 'lowincome' and 'poverty' featuring in the top 20 most frequent words. Respondents also acknowledged the necessity of more social housing, with words like 'necessary,' 'underfunded,' 'inadequate,' 'we need more!' and 'important' emerging frequently, reflecting the 'structural' narrative identified by Jacobs and Flanagan (2013). A racialized view of social housing was also apparent, evidenced in the use of words like 'refugees,' 'immigrants,' 'migrants,' 'ethnic,' 'multicultural' and 'African.' The themes also encompassed comments on the built form of social housing including words like 'high-rise,' 'tower,' 'ugly, ' dirty,' 'brick,' 'brown,' 'messy' and 'rubbish.' Finally, a pathological narrative was also apparent, with words like 'drugs,' 'crime' and 'unsafe' featuring in responses.

In contrast, social housing residents chose a more positive or neutral range of words. Terms related to home and community occurred frequently with respondents using lists like "friendly, home, sense of community, family, friends" or referring to their gratitude to be living where they are. One respondent wrote, "good place to live in, affordable housing rent." However, other respondents painted a less positive picture saying things like "lack of security, Africans run amuck, security guards running ice" and "dirty, messy, bad, noisy." Another theme emerged that focussed predominantly on the amenities in their neighbourhood, highlighting things like convenience, transport, shopping and medical services. Cultural diversity and diversity more generally were a key theme in these responses, but terms common to private residents, like immigrant, asylum or refugee were notably absent. 

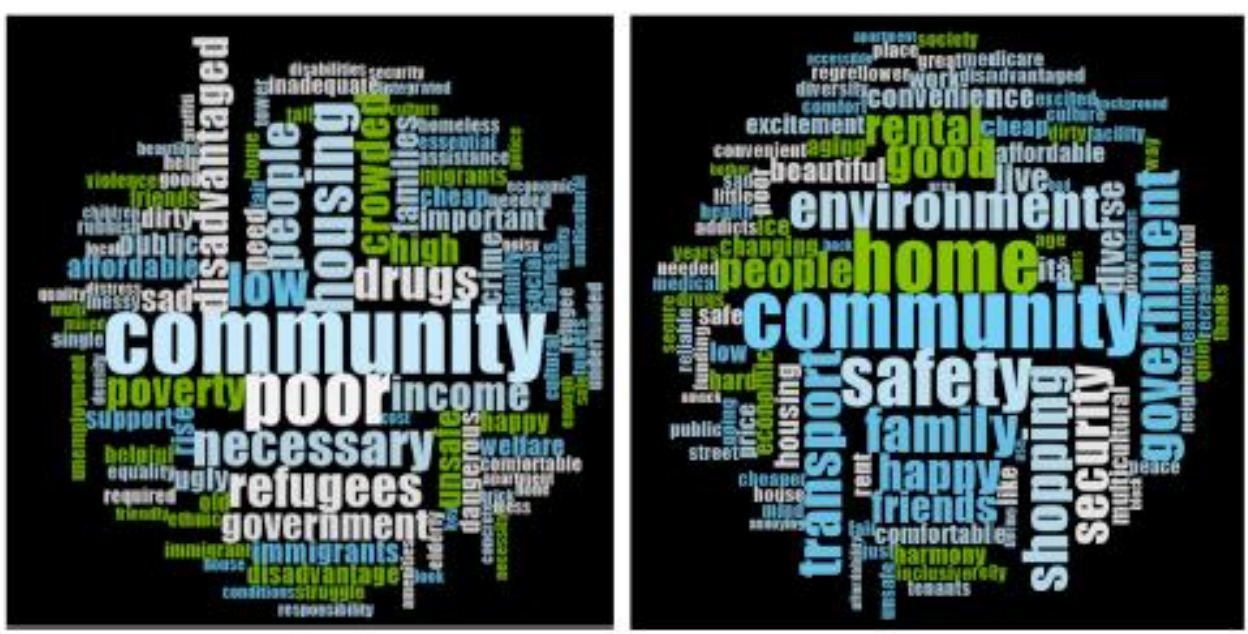

Figure 2: The first five words about social housing reported by survey respondents. 
Table7: Private residents vs. public resident ideas associated with public housing estates.

\begin{tabular}{|c|c|c|c|c|}
\hline \multirow[t]{2}{*}{ Wond ID } & \multicolumn{2}{|l|}{ Private restdents } & \multicolumn{2}{|c|}{ Public residents } \\
\hline & Word & Count & Wond & Count \\
\hline 1 & Community & 25 & Community & 14 \\
\hline 2 & Poor & 20 & Home & 13 \\
\hline 3 & Houstng & 18 & Safety & 12 \\
\hline 4 & Dlsadvantaged & 15 & Security & 10 \\
\hline 5 & Refugees & 15 & Environment & 9 \\
\hline 6 & Drugs & 13 & Family & 9 \\
\hline 7 & Low & 13 & Govemment & 9 \\
\hline 8 & Necessary & 13 & Shopplng & 9 \\
\hline 9 & People & 12 & Transport & 9 \\
\hline 10 & Crowded & 11 & Good & 8 \\
\hline 11 & Familles & 11 & Happy & 8 \\
\hline 12 & Inœme & 10 & Diverse & 7 \\
\hline 13 & Need & 10 & Friends & 7 \\
\hline 14 & Poverty & 10 & Lve & 7 \\
\hline 15 & Govemment & 9 & People & 7 \\
\hline 16 & Immigrants & 9 & Rental & 7 \\
\hline 17 & Helpful & 8 & Conventence & 6 \\
\hline 18 & High & $\mathrm{B}$ & Excitement & 6 \\
\hline 19 & Sad & 8 & Houstng & 6 \\
\hline 20 & Affardable & 7 & AgIng & 5 \\
\hline
\end{tabular}

\section{Discussion}

In line with recent research on public housing residents (Arthurson et al., 2014; Kearns et al., 2013), our findings identify that the presence of stigma directed at social housing residents is attached to fears about crime and social deviance, negative opinions about the built form of public housing estates and a racialised discourse about tenants. We found higher levels of stigmatisation in older groups, private housing residents, and lower income respondents. The impact of higher income on more positive attitudes towards social housing has precedence in the literature (Ziersch et al., 2018) and may reflect the propensity for 'lower status' (or lower income) groups to seek to increase their status by distancing themselves from stigmatised groups through downward comparison (Belcher \& DeForge, 2012).

Certainly, prior research on low income, former social housing tenants that moved into homeownership in Melbourne found the presence of stigma and avoidance tactics towards previous 'flawed' neighbours (Name redacted for anonymity, 2018).

Significantly, while private housing residents expressed a higher level of stigma than residents of public housing, public housing responses also reflected internalised stigma. These differences in stigma ratings exist despite public housing tenants being far more likely to report negative interactions with other public housing residents. In contrast, private housing residents displayed relatively low levels of contact with public housing residents and, of this group, only a small share reported bad interactions. While this response is probably artificially low as contact is occurring without private housing residents being aware of the tenure status of the people they meet, it is also evidence of the cognitive bias known as the availability heuristic that drives stereotyping among people with limited exposure to a stigmatized group. The availability heuristic often leads people to make assumptions about stigmatised group members based on stereotypes, i.e., the only available information most people have about a group they know little about (Tversky \& Kahneman, 1973).

This study provides interesting and novel insights for the social mix literature and social contact theory. We found a complex relationship between interactions with social housing tenants and built form and stigma. Namely, contact with social housing tenants per se is not associated with change in stigma levels, lending credence to multiple studies that have questioned the efficacy of simply collocating social and private housing and expecting positive results (Arthurson et al., 2014; McCormick et al., 2012). As Lee et 
al.'s (2004) study found, frequent exposure to an out-group may generate avoidance tactics or a lack of empathy for some members of the population. However, we find that positive interactions and proximity to Kensington Estate, a mixedtenure development, contribute to lower stigmatisation. This means that social contact theory's predictions (Pettigrew, 1998) appear only valid in the context of public housing when people experience positive interactions with public housing residents. Although not explicitly asked in the survey, conversations with survey respondents suggest that facilities like the community centre and playground played a significant role in driving interactions between public and private housing residents in Kensington.

These results must be interpreted with caution. Our dataset does not represent a random or probabilistic social sample given the convenience sampling technique used. However, this technique did permit us to collect data from the people whose experiences are the most immediate and relevant to the public housing estates. There is undeniably a self-selection bias in people who choose to visit social housing estates and the community facilities in and near them. Literature often finds higher sense of community in individuals who attend community activities or events (Miranti \& Evans, 2019), potentially biasing surveys conducted at events or activities at or near the estates, particularly in Kensington where community facilities are more integrated shared spaces for public and private housing residents. Given Kensington and Flemington Estates were built at similar times and, before renewal, featured similar architectural features and demographic characteristics, they otherwise represent useful comparative examples.

There is also likely a social desirability bias with the responses obtained via face-to-face surveying, despite us not observing a statistically significant difference in stigma level by survey collection technique. A bigger dataset may allow future research to test for these differences, if they do exist. Our findings suggest that demographic characteristics and attitudes towards diversity are far more significant in predicting stigma than is proximity to public housing. Such findings echo insights from Norris et al. (2018) that suggest that simply designing neighbourhoods that place public and private housing residents in close proximity may be less effective than other approaches, such as education and marketing tactics, that encourage private housing residents to challenge their assumptions about public housing.

Yurning to the words used to describe social housing, this research indicates both a "blemish of place" (Wacquant, 2007) and a "spoiled identity" (Goffman, 1986) in the narratives used by respondents. Words used to describe public housing differed greatly between public and private housing residents, reflecting the common finding that 'insiders' of a neighbourhood rarely perceive their home as negatively as 'outsiders.' Indeed, social housing is often home to strong community connections and sense of place (Manzo, Kleit, \& Couch, 2008; McKenzie, 2012). Public housing tenants were far more likely to focus on positive or neutral terms, reflecting a finding that showed that average housing satisfaction was almost as high for public housing tenants as private residents. Similarly, the words used to describe public housing demonstrate the degree to which residents of public housing resist 'othering' narratives. As one respondent explained "Nothing comes to mind [when describing public housing], it's just home". In contrast, private resident words often related to overcrowding, brown and ugly buildings, high density development and aging buildings, suggesting that location and architecture colour attitudes towards social housing. However, this study suggests that high levels of stigma are not universal and, in fact, there is a wide-spread acknowledgement of the structural problems surrounding social housing. Attitudes towards social housing also relate to the housing system more generally, as responses consider the underfunded system, the necessity of additional funding and disinvestment that has led to social housing outcomes. These responses, that emerge from a question investigating social housing broadly rather than a particular estate or location, point to relatively broad support for social housing per se. Further research 
could fruitfully investigate whether an acknowledgement of the underfunded nature of social housing correlates with higher acceptance of specific local social housing developments.

Our study finally identifies the multilayered ways in which stigma is experienced. More than a third of public housing residents indicated that they believed they had been discriminated against when seeking employment. While a proportion suggested this was related to where they live, respondents also listed ethnicity, religion, age, gender and caring responsibilities as reasons. This finding is unsurprising given the residualisation of the social housing system that is targeted almost exclusively at extremely low income and high vulnerability households. It

is particularly relevant in the context of social mix strategies that do nothing to challenge structural issues associated with other 'identity markers' and unequal access to resources and opportunities. The prevalence of racialised discourses in responses is important here, particularly as it relates to broader discourses about immigrants and asylum seekers. As Keene and Padilla (2010) found, it may be that race-based stigma will travel with residents regardless of tenure or neighbourhood.

\section{Conclusion}

This research reflects the first phase in a longitudinal study of the changing landscape of stigma in redeveloping public housing estates. The current paper builds on previous evidence of such communities by providing a more quantitative foundation for stigmatisation of social housing using data derived from surveys conveniently delivered to both public and private housing residents in Melbourne, Australia. This complements a body of literature that has predominately used focus groups and interviews to assess stigma. We build on the existing body of literature that questions the validity of narratives that suggest that proximity and propinquity between social and private housing and residents will necessarily lead to reduced stigmatisation of places and people. Our research suggests that such patterns may be occurring in the context of one mixed-tenure development in Melbourne, Australia. However, this relationship is complex and may reflect self-selection biases inherent in decisions to use facilities in and around this estate. Understanding this relationship may involve refining the methods presented and building more demographically representative datasets of people's perception of public housing stigma. We contribute a new insight into who is most likely to stigmatise (private housing residents, older residents, long-term residents), the impact of proximity to estates (proximity to Kensington Estate reduces stigma) and the pathological and structural narratives surrounding social housing.

\section{Ethics statement}

Ethics approval for research with human subjects was obtained from the University (Ethics ID Number: 1852454.1). Informed consent was obtained from all participants by describing the study verbally during intercept surveys and by including a consent format and plain language statement of the research on the first page of the online and printed surveys.

\section{Declaration of Competing Interest}

The authors declare that they have no known competing financial interests or personal relationships that could have appeared to influence the work reported in this paper.

\section{Acknowledgements}

This research was funded by the Economic \& Social Participation Research Initiative (ESPR/t), Hallmark Initiative, University of Melbourne. $\mathrm{CO}$ is supported by funding from the Australian Research Council (ARC) Linkage Partnership grant (LP16010078). The team is grateful to the contributions of Jenny Pitts, 
Morgan Cataldo, Elma Khan and Dr. Matthew Palm in supporting this project. We likewise acknowledge the valuable contributions of Erika, Sandra, Philip, Victor, Mahir and Hadia in workshopping the survey instrument developed for this study.

\section{References}

Algan, Y., \& Cahuc, P. (2010). Inherited trust and growth. American Economic Review, 100(5), 2060-2092. https://doi.org/10.1257/aer.100.5.2060.

Arthurson, K. (2008). Australian public housing and the diverse histories of social mix. Journal of Urban History, 34(3), 484-501. https://doi.org/10.1177/0096144207311192.

Arthurson, K. (2012). Social mix and the city: Challenging the mixed communities consensus in housing and urban planning policies. Melbourne: CSIRO Publishing.

Arthurson, K., Darcy, M., \& Rogers, D. (2014). Televised territorial stigma: How social housing tenants experience the fictional media representation of estates in Australia. Environment and Planning A: Economy and Space, 46(6), 1334-1350. https://doi.org/10.1068/a46136.

Atkinson, R., \& Jacobs, K. (2008). Public housing in Australia: Stigma, home and opportunity. Housing and community research unit. University of Tasmania.

August, M. (2014). Challenging the rhetoric of stigmatization: The benefits of concentrated poverty in Toronto's Regent Park. Environment and Planning A: Economy and Space, 46(6), 1317-1333. https://doi.org/10.1068/a45635.

Australian Institute of Health and Welfare (2018). Housing assistance in Australia 2018. Retrieved from Australian Government website: https://www.aihw.gov.au/reports/housingassistance/housingassistance-in-australia-2018/ .

Bauder, H. (2002). Neighbourhood effects and cultural exclusion. Urban Studies, 39(1), 85-93. https://doi.org/10.1080/00420980220099087.

Belcher, J. R., \& DeForge, B. R. (2012). Social stigma and homelessness: The limits of social change. Journal of Human Behavior in the Social Environment, 22(8), 929-946. https://doi.org/10.1080/10911359.2012.707941.

Blokland, T. (2008). Facing violence: Everyday risks in an American housing project. Sociology, 42(4), 601617. https://doi.org/10.1177/0038038508091617.

Burke, T., Neske, C., \& Ralston, L. (2004). Entering rental housing. Australian Housing and Urban Research Institute.

Carnegie, A., Norris, M., \& Byrne, M. (2018). Tenure mixing to combat public housing stigmatization: External benefits, internal challenges and contextual influences in three Dublin neighborhoods. Cities, 79, 12-17. https://doi.org/10.1016/j.cities.2018.02.017.

Corbin, J. M., \& Strauss, A. (1990). Grounded theory research: Procedures, canons, and evaluative criteria. Qualitative Sociology, 13(1), 3-21. https://doi.org/10.1007/ BF00988593.

Crocker, J., Major, B., \& Steele, C. (1998). Social stigma. In S. T. Fiske, D. T. Gilbert, G. Lindzey, \& A. E. Jongsma (Vol. Eds.), Handbook of social psychology(1st ed.). Vol. 2. Handbook of social psychology (pp. 504-553). Hoboken, N.J: Wiley.

Dillman, D. A., Smyth, J. D., \& Christian, L. M. (2014). Internet, phone, mail, and mixedmode surveys: The tailored design method (4th ed.). Hoboken, NJ, US: John Wiley \& Sons, Inc528.

Fernández, R. (2007). Women, work, and culture. Journal of the European Economic Association, 5(2-3), 305-332. https://doi.org/10.1162/jeea.2007.5.2-3.305.

Goetz, E. G. (2013). The audacity of HOPE VI: Discourse and the dismantling of public housing. Cities, 35, 342-348. https://doi.org/10.1016/j.cities.2012.07.008.

Goffman, E. (1986). Stigma: Notes on the management of spoiled identity (26th pr). New York: Simon \& Schuster. 
Hastings, A., \& Dean, J. (2003). Challenging images: Tackling stigma through estate regeneration. Policy \& Politics, 31(2), 171-184. https://doi.org/10.1332/ 030557303765371663

Hatzenbuehler, M. L., Phelan, J. C., \& Link, B. G. (2013). Stigma as a fundamental cause of population health inequalities. American Journal of Public Health, 103(5), 813-821. https://doi.org/10.2105/AJPH.2012.301069.

Hayward, D. (1996). The reluctant landlords?: A history of public housing in Australia. Urban Policy and Research, 14(1), 5-35. https://doi.org/10.1080/08111149608551610.

Hunt, D. B. (2010). Blueprint for disaster: The unraveling of Chicago public housing (Paperback ed.). Chicago London: University of Chicago Press.

Jacobs, K., \& Flanagan, K. (2013). Public housing and the politics of stigma. Australian Journal of Social Issues, 48(3), 319-337. https://doi.org/10.1002/j.1839-4655.2013.tb00285.x.

Joseph, M., \& Chaskin, R. (2010). Living in a mixed-income development: Resident perceptions of the benefits and disadvantages of two developments in Chicago. Urban Studies, 47(11), 2347-2366. https://doi.org/10.1177/0042098009357959.

Joseph, M., Chaskin, R., \& Webber, H. (2007). The theoretical basis for addressing poverty through mixedincome development. Urban Affairs Review, 42(3), 369-409. https://doi.org/10.1177/1078087406294043.

Kearns, A., Kearns, O., \& Lawson, L. (2013). Notorious places: Image, reputation, stigma. The role of newspapers in area reputations for social housing estates. Housing Studies, 28(4), 579-598. https://doi.org/10.1080/02673037.2013.759546.

Keene, D. E., \& Padilla, M. B. (2010). Race, class and the stigma of place: Moving to "opportunity" in Eastern lowa. Health \& Place, 16(6), 1216-1223. https://doi.org/10.1016/j.healthplace.2010.08.006.

Lee, B. A., Farrell, C. R., \& Link, B. G. (2004). Revisiting the contact hypothesis: The case of public exposure to homelessness. American Sociological Review, 69(1), 40-63. https://doi.org/10.1177/000312240406900104.

Lucine, B. (2018). The eviction (FKA on the rocks) [documentary]. Retrieved from https://2ser.com/theeviction-documentary-film/.

Manzo, L. C., Kleit, R. G., \& Couch, D. (2008). "Moving three times is like having your house on fire once": The experience of place and impending displacement among public housing residents. Urban Studies, 45(9), 1855-1878. https://doi.org/10.1177/0042098008093381.

McCormick, N. J., Joseph, M., \& Chaskin, R. J. (2012). The new stigma of relocated public housing residents: Challenges to social identity in mixed-income developments. City \& Community, 11(3), 285-308. https://doi.org/10.1111/j.1540-6040.2012.01411.x.

McKenzie, L. (2012). A narrative from the inside, studying St Anns in Nottingham: Belonging, continuity and change. The Sociological Review, 60(3), 457-475. https://doi.org/10.1111/j.1467954X.2012.02094.X.

Miranti, R., \& Evans, M. (2019). Trust, sense of community, and civic engagement:

Lessons from Australia. Journal of community psychology, 47(2), 254-271. Musterd, S., \& Andersson, R. (2005). Housing mix, social mix, and social opportunities. Urban Affairs Review, 40(6), 761-790. https://doi.org/10.1177/1078087405276006.

Norris, M., Byrne, M., \& Carnegie, A. (2018). Combatting stigmatisation of social housing neighbourhoods in Dublin, Ireland. International Journal of Housing Policy, 1-13. https://doi.org/10.1080/19491247.2018.1532673.

Palmer, C., Ziersch, A., Arthurson, K., \& Baum, F. (2004). Challenging the stigma of public housing: Preliminary findings from a qualitative study in South Australia. Urban Policy and Research, 22(4), 411-426. https://doi.org/10.1080/0811114042000296326. 
Patulny, R. V., \& Morris, A. (2012). Questioning the need for social mix: The implications of friendship diversity amongst Australian social housing tenants. Urban Studies, 49(15), 3365-3384. https://doi.org/10.1177/0042098012442414.

Pettigrew, T. F. (1998). Intergroup contact theory. Annual Review of Psychology, 49(1), 65-85. https://doi.org/10.1146/annurev.psych.49.1.65.

Raynor, K. (2018). Assembling an innovative social housing project in Melbourne: Mapping the potential for social innovation. Housing Studies, 1-23. https://doi.org/10.1080/02673037.2018.1535054.

Ruming, K. (2015). Everyday discourses of support and resistance: The case of the Australian social housing initiative. Housing, Theory and Society, 32(4), 450-471. https://doi.org/10.1080/14036096.2015.1048896.

Shaw, K. (2017). Inquiry into the public housing renewal program: Submission from Dr Kate Shaw. Retrieved from STANDING COMMITTEE ON LEGAL AND SOCIAL ISSUES website: https://www.parliament.vic.gov.au/images/stories/committees/SCLSI/Public_Housing_Renewal_ Program/Submissions/S3-Dr_Kate_Shaw.pdf.

Tach, L. M. (2009). More than bricks and mortar: Neighborhood frames, social processes, and the mixedincome redevelopment of a public housing project. City \& Community, 8(3), 269-299. https://doi.org/10.1111/j.1540-6040.2009.01289.x.

Taylor, S. M., \& Dear, M. J. (1981). Scaling community attitudes toward the mentally ill. Schizophrenia Bulletin, 7(2), 225-240. https://doi.org/10.1093/schbul/7.2.225.

Tversky, A., \& Kahneman, D. (1973). Availability: A heuristic for judging frequency and probability. Cognitive Psychology, 5(2), 207-232. https://doi.org/10.1016/0010-0285(73)90033-9.

van Ham, M., \& Feijten, P. (2008). Who wants to leave the neighbourhood? The effect of being different from the neighbourhood population on wishes to move. Environment and Planning A: Economy and Space, 40(5), 1151-1170. https://doi.org/10.1068/a39179.

Varady, D. P., \& Matos, F. (2017). Comparing public housing revitalization in a liberal and a Mediterranean society (US vs. Portugal). Cities, 64, 37-46. https://doi.org/10.1016/j.cities.2017.01.007.

Wacquant, L. (2007). Territorial stigmatization in the age of advanced marginality. Thesis Eleven, 91(1), 66-77. https://doi.org/10.1177/0725513607082003.

Ziersch, A., Arthurson, K., \& Levin, I. (2018). Support for tenure mix by residents local to the Carlton Housing Estate, Melbourne, Australia. Housing Studies, 33(1), 58-76. https://doi.org/10.1080/02673037.2017.1344201. 